\title{
Cementless Bilateral Total Hip Arthroplasty in a Patient with a History of Pelvic Irradiation for Sarcoma Botryoides
}

\author{
Emre Demircay $^{a}$ Koray Unay ${ }^{b}$ Nadir Sener ${ }^{c}$ \\ Departments of Orthopedics and Traumatology, ${ }^{a}$ Istanbul Medical Center, Baskent University School of Medicine, \\ Istanbul, ${ }^{\mathrm{b}}$ Goztepe Research and Training Hospital, Istanbul, and ' Bursa Acibadem Hospital, Bursa, Turkey
}

\section{Key Words}

Hip · Arthroplasty, cementless · Radiotherapy · Sarcoma botryoides

\begin{abstract}
Objective: To report a case of bilateral secondary coxarthrosis in a patient with a history of pelvic irradiation for sarcoma botryoides. Clinical Presentation and Intervention: The patient had surgery and radiation therapy for sarcoma botryoides when she was 18 months old. Left and right cementless total hip arthroplasties were performed at the age of 36 and 40 years, respectively. Harris hip scores improved from 28.4 to 93 on the left hip after 84 months of follow-up and from 29.5 to 91.3 on the right hip after 38 months of followup. Conclusion: Cementless total hip arthroplasty may be considered for irradiated hips, if radiation damage in bone has been stable for a long period of time.
\end{abstract}

Copyright $\odot 2009$ S. Karger AG, Basel

\section{Introduction}

Osteonecrosis, rarefaction of bone and coarsening of trabeculae are well-documented and defined complications of radiation therapy. Bone growth retardation as a result of radiation was described as early as 1903 by Perthes [1].

Sarcoma botryoides is a variety of embryonal rhabdomyosarcoma, arising in submucosal tissue, presenting grossly as a polypoid grape-like structure and occurring most often in young children or infants in the upper vagina, cervix uteri or neck of the urinary bladder [2].

Total hip arthroplasty after pelvic irradiation has been reported to have unfavorable results $[1,3,4]$. Early acetabular loosening is the main cause of failure. Bony ingrowth into the acetabular component may be impaired by radiation damage [4]. Several investigators have suggested the use of cemented acetabular components with or without augmentation rings $[1,4]$. However, the duration of the negative effects of the pelvic radiotherapy has not been established. Much more important is the poor bone quality. Although a cementless acetabular cup is generally preferred in young patients, cemented hip prosthesis is recommended for patients who have undergone radiotherapy. Whether or not cementless total hip arthroplasty can be performed in these patients after a certain period of time is not yet known. We report successful bilateral cementless total hip arthroplasty in a female patient with a history of pelvic irradiation 38 years previously.

\section{KARGER}

Fax +4161306 1234

E-Mail karger@karger.ch

www.karger.com (c) 2009 S. Karger AG, Basel

1011-7571/09/0185-0411\$26.00/0

Accessible online at:

www.karger.com/mpp
Emre Demircay

Department of Orthopedics and Traumatology

Istanbul Medical Center, Baskent University School of Medicine

TR-34662 Istanbul (Turkey)

Tel. +90 216554 1500, Fax +90 212275 4082, E-Mail emredemircay@ttnet.net.tr 


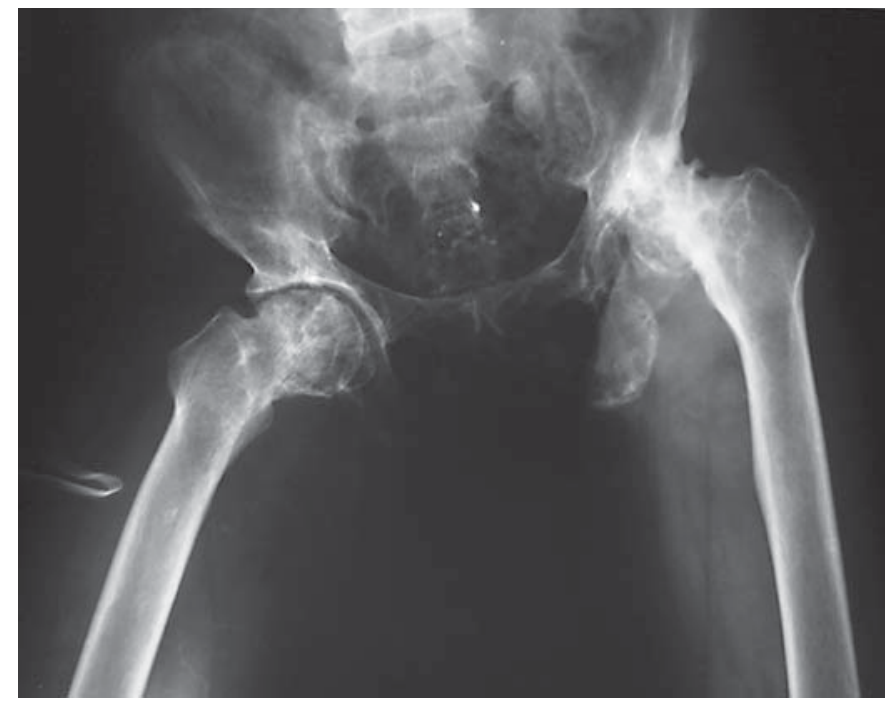

Fig. 1. Areas of rarefaction and sclerosis in both hips and proximal migration of the left hip.

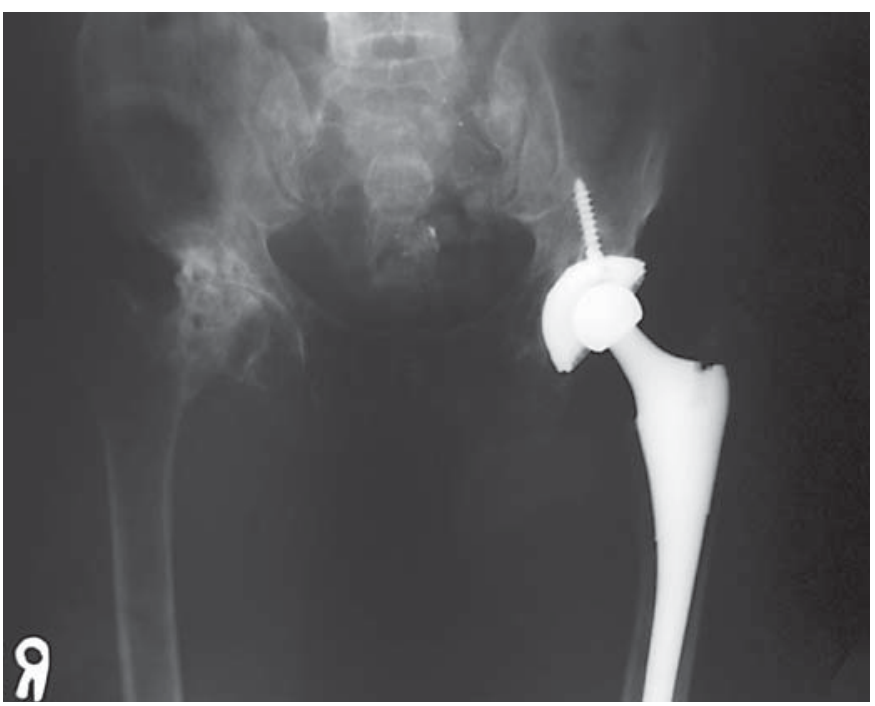

Fig. 2. Sclerotic bone was reamed. The acetabular cup had good contact with the bone.

\section{Case Report}

A female patient with a history of sarcoma botryoides underwent cementless total hip arthroplasty on her left hip in 2001 and on her right hip in 2005. At the age of 18 months, she had been treated for sarcoma botryoides in 1967, when she had total hysterectomy, cystectomy, bilateral ureterocutaneostomy and postoperative pelvic radiotherapy. She did not have any major postoperative complications and had had no recurrence since then.

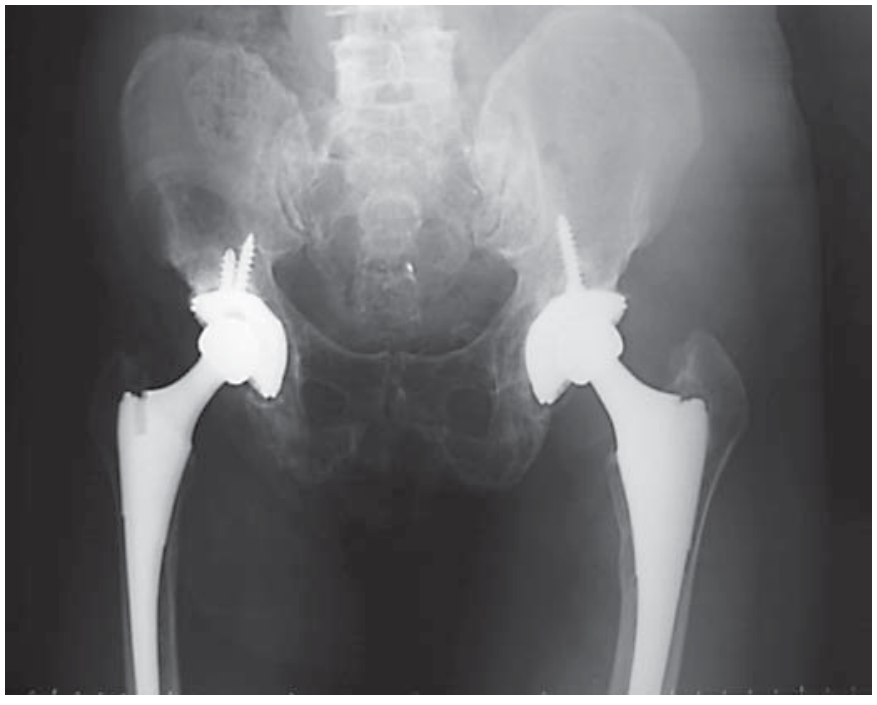

Fig. 3. Left and right total hip arthroplasty at 84 and 38 months after the operation. A nonprogressive radiolucent line can be seen on the right acetabulum in zones I and II.

Although she had been on hormone replacement therapy since the age of 9 , she was osteopenic at the time of arthroplasty. Her anterior-posterior spine and proximal femur double-energy Xray absorptiometry results showed $\mathrm{T}$ scores of -2.1 and -1.6 , respectively. She had a small stature (height: $150 \mathrm{~cm}$, weight $50 \mathrm{~kg}$ ). Her pelvic dimensions were even smaller for her size, probably due to postirradiation growth arrest. The transverse diameters of the pelvic outlet were $8.5 \mathrm{~cm}$ (bituberous diameter, between the inner aspects of the ischial tuberosities, normal $=11 \mathrm{~cm}$ ) and $7.5 \mathrm{~cm}$ (bispinous diameter, between the tips of ischial spines, normal $=10.5 \mathrm{~cm})$.

At the age of 30 years, her left hip became symptomatic due to progression of pain over time. At the age of 36 years, she underwent total hip arthroplasty on her left hip. Preoperative roentgenograms showed areas of rarefaction and sclerosis in both hips; joint space narrowing and deformation of the femoral heads were observed, and the left femoral head was subluxated (fig. 1). Four years later (age 40 years) although she did not have any problems on the left side, she needed right total hip arthroplasty. Her radiographs showed further narrowing of the right hip joint space (fig. 2).

Her hips had a very limited range of motion, and her left hip had adduction contracture. Both hips had similar surgical details; the standard posterior-lateral approach was used after percutaneous adductor tenotomy. Total capsulectomy and partial release of the gluteus maximus tendon were done in order to mobilize the femur and to improve exposure. A $42-\mathrm{mm}$ porous coated press-fit acetabular shell with 2 screws and 22 -mm cross-linked polyethylene liner (Reflection, Smith \& Nephew Orthopedics, Memphis, Tenn., USA) were implanted. Since trial reduction could not be performed, the iliopsoas tendon was released, and then partial division of the gluteus medius tendon was done. Size 11 and 9 proximal porous coated femoral stems with $22-\mathrm{mm}$ cobalt-chromium heads were implanted into the left and right femurs, respectively (Synergy, Smith \& Nephew Orthopedics). 
Eighty-four months after her left and 38 months after her right hip operation, follow-up roentgenograms showed a nonprogressive radiolucent line at the right acetabular cup in zones I and II (fig. 3). Otherwise all the components were stable. Her Harris hip scores improved from 28.4 and 29.5 to 93 and 91.3 for her left and right hips, respectively.

\section{Discussion}

Total hip arthroplasty in patients with previous pelvic irradiation reportedly has high failure rates $[1,3,4]$. In a series of patients implanted with hemispherical porous coated acetabular components after previous pelvic irradiation, 4 out of 9 (44.4\%) hips failed at an average of 25 months [1]. In another study, patients with cemented acetabular components had a $52 \%$ acetabular and $12 \%$ femoral failure rate at a mean follow-up of 69 (range 6-240) months. Early acetabular loosening was reported, usually within the first 4 postoperative years. Reinforcement rings decreased the failure rate to $31.2 \%$ at a mean followup of 40 months [4]. They are believed to improve fixation to the healthy bone and transmission of weight-bearing stresses. However, the infection rate was significantly greater with reinforcement rings [4].

Progressive deterioration of periacetabular bone has been noted as late as 14 years after radiation exposure [3]. It is advised that the response of bone to a major dose of radiation must be followed over time [1]. However, irradiated bone remains viable to a certain extent, since some blood supply is maintained and is often sufficient to support some new bone formation, fracture healing and perhaps the incorporation of bone grafts [4].

As far as we know, the longest interval between radiotherapy and total hip replacement reported in the literature is 23 years [4]. In our patient, the interval of 38 years was considerably longer. Her radiographs showed no further radiation-induced changes from 1995 to her operation in 2001. She had a very small pelvis and both of her acetabula had a thick layer of sclerotic bone. She was not expected to have enough acetabular bone stock to make it possible to ream away the necrotic bone, but at surgery, when healthy bleeding bone was seen, a cementless acetabular component was preferred. A reinforcement ring with an all-poly cup was saved as an option for this patient in case aseptic loosening occurs in the future.

The radiolucent line at the right acetabulum was first noted 12 months after surgery. It had not progressed at the last follow-up, and she had no associated clinical symptoms (fig. 3 ).

Bone viability should be carefully assessed if a cementless acetabular cup is considered in a previously irradiated hip. We did not observe any evidence of loosening of the stems during the early follow-up for right hip and midterm follow-up for the left hip. The interval between the radiation therapy and total hip arthroplasty may be an important factor for osseous integration of the porous coated prosthesis.

\section{Conclusion}

Cementless total hip arthroplasty may be considered for irradiated hips, if radiation damage in bone has been stable for a long period of time.

\begin{tabular}{|c|c|}
\hline References & $\begin{array}{l}\text { Jacobs JJ, Kull LR, Frey GA, Gitelis S, } \\
\text { Sheinkop MB, Kramer TS, Rosenberg AG: } \\
\text { Early failure of acetabular components in- } \\
\text { serted without cement after previous pelvic } \\
\text { irradiation. J Bone Joint Surg Am 1995;77: } \\
1829-1835 \text {. } \\
\text { B } \\
\text { Brand E, Berek JS, Nieberg RK, Hacker NF: } \\
\text { Rhabdomyosarcoma of the uterine cervix: } \\
\text { sarcoma botryoides. Cancer 1987;60:1552- } \\
1560 \text {. } \\
\text { 3eleeuw H, Pottenger LA: Osteonecrosis of } \\
\text { the acetabulum following radiation therapy: } \\
\text { a report of two cases. J Bone Joint Surg Am } \\
\text { 1988;70:293-299. } \\
4 \text { Massin P, Duparc J: Total hip replacement in } \\
\text { irradiated hips: a retrospective study of } 71 \\
\text { cases. J Bone Joint Surg Br 1995;77:847-852. }\end{array}$ \\
\hline
\end{tabular}

